\title{
Motor Coordination Training and Pedagogical Approach for Combating Childhood Obesity
}

\author{
Allan Chak Lun Fu, Stephen Paul Cobley, Ross Howard Sanders \\ Discipline of Exercise and Sport Science, The University of Sydney, Sydney, Australia \\ Email:allan.fu@sydney.edu.au, stephen.cobley@sydney.edu.au,ross.sanders@sydney.edu.au
}

How to cite this paper: Fu, A., Cobley, S.P. and Sanders, R.H. (2016) Motor Coordination Training and Pedagogical Approach for Combating Childhood Obesity. Open Journal of Social Sciences, 4, 1-12. http://dx.doi.org/10.4236/jss.2016.412001

Received: October 18, 2016

Accepted: November 28, 2016

Published: December 2, 2016

Copyright $\odot 2016$ by authors and Scientific Research Publishing Inc. This work is licensed under the Creative Commons Attribution International License (CC BY 4.0).

http://creativecommons.org/licenses/by/4.0/ (c) (i) Open Access

\begin{abstract}
Evidence suggests that obesity is strongly associated with low physical activity (PA). Overcoming the obesity problem requires that individuals adhere to prescribed PA programs. Therefore, in this paper we review the factors affecting adherence. On the basis of the review we recommend a strategy for developing movement competence and enjoyment of PA to improve adherence and long term participation in PA. The relationships among childhood obesity, level of PA, and movement competence indicated by motor coordination (MC) and development of fundamental movement skills (FMS) were reviewed, followed by an assessment of current pedagogical and psychological principles leading to the proposal of a strategic approach to improve long term PA adherence. Many children are affected by a "vicious cycle of obesity", low PA, and low levels of movement competence perpetuating avoidance of PA. Intervention programmes to break the vicious cycle should be based on skill development needs of individuals. The program should be designed and delivered in a manner that fosters a task-based psycho-social climate based on self-determination and achievement goal theories. MC training reinforced by a favourable psycho-social climate can be effective in breaking a "vicious cycle of obesity" and increasing PA adherence.
\end{abstract}

\section{Keywords}

Physical Activity, Obesity, Motor Coordination, Fundamental Movement Skills

\section{Introduction}

Obesity is defined as abnormal or excessive fat accumulation that may impair health [1]. It is regarded as a worldwide epidemic and a global public health burden [2]. Based on current trends, the number of overweight and obese individuals in the world has been projected to reach 3.38 billion by 2030 [3], and so both direct and indirect health 
care costs (e.g. loss of productivity and health morbidities) are expected to rise considerably [4] [5]. Childhood obesity has long-term adverse consequences. For instance, overweight and obese children are six times more likely to be obese in adulthood relative to their normal weight peers [6], are at heightened risk of type-2 diabetes, hypertension, chronic heart disease [7] [8] [9], and are more strongly associated with physical morbidity [8] [10] [11], premature mortality [8], and psycho-social co-morbidity [10]. If the obesity problem can be alleviated, long term quality of life will be improved [12], but also the long-term medical costs [12] and social burden [3] [4] [5] can be reduced. Raising PA levels has been identified, promoted, and examined as one main strategy to control and reduce obesity [13]. However, current PA intervention strategies are not effective in increasing and sustaining PA participation at levels sufficient to achieve health benefits [14]. Thus, whilst considering the reasons for compromised PA adherence, a new strategy for effective PA intervention is urged [15].

While the link between PA and obesity is well established, we propose that movement competency is a third component of a "vicious cycle of obesity". In this paper, the relationships among childhood obesity, level of PA and movement competency indicated by motor coordination (MC) and development of fundamental movement skills (FMS) are reviewed, followed by an assessment of current pedagogical and psychological principles leading to the proposal of a new strategic approach to break that cycle to encourage long term PA adherence.

\subsection{The Vicious Cycle of Obesity}

The vicious cycle of obesity concept (Figure 1) is based on evidence from a number of systematic reviews and meta-analyses [16]-[21], longitudinal studies [22] [23] [24] [25] and large scale cross-sectional studies [26] [27] [28]. Here PA encapsulates all types of

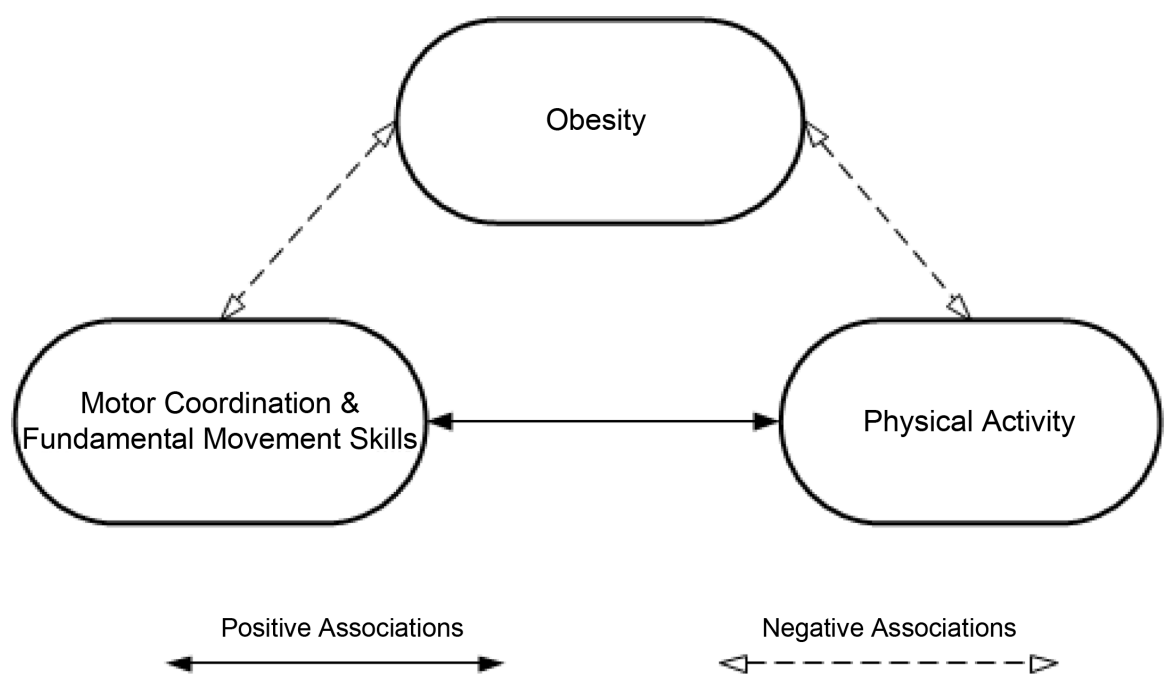

Figure 1. Diagrammatic representation of the vicious cycle of obesity. A "vicious cycle of obesity" is comprised of obesity, low levels of physical activity participation, and poor levels of motor coordination and fundamental movement skills. The positive and negative associations between these factors are illustrated by solid and dashed arrows respectively. 
body movements produced by skeletal muscles that require energy expenditure, including exercise, fitness training, sports, active play, games, physical education and routine activities accumulated during daily living, regardless of the settings, purposes and intensity of activities [29] [30]. MC is traditionally defined as the ability to control the degrees of freedom (DOF) to achieve a goal-oriented movement as described by Bernstein [31] and is further elaborated as a proper relation of head, body and limb movements relative to environmental objects and events by Turvey [32]. Thus, we define MC as the ability to control the wide range of DOFs and maintain functional temporal and spatial relations among body segments, environmental objects and events to achieve goal-oriented movements. FMS refer to an organized series of observable basic movements [33] and are categorised functionally into locomotion (e.g. running and hopping) and object control (e.g., throwing, kicking, and striking) [19] [20] [21] [33] [34]. FMS are regarded as the foundations or "building blocks" for performing more complex sports skills [19] [20] [33] [35] (e.g., a "jump-shot" in basketball). Having movement competence as an adolescent entails having developed appropriate MC to perform each of the specific FMS at a level sufficient to enable confident participation in peer group activities.

Obesity in children and adolescents is consistently and negatively correlated with PA, as demonstrated in a number of systematic reviews [16] [17] [18]. For instance, based on a review of longitudinal and cross-sectional studies, Jiménez-Pavón, et al. [16] identified negative correlations in 38 out of 48 (79\%) studies. This was irrespective of age range, sample size, and method of estimating body composition [i.e. absolute body mass index (BMI) or BMI z-score] and PA measurements (i.e. accelerometer, pedometer and heart rate measurement). Similarly, Prentice-Dunn and Prentice-Dunn [17] found that PA was negatively associated with child BMI status in 11 of 16 (69\%) cross-sectional studies. By contrast, Vasconcellos, et al. [18] identified that PA was positively associated with physical fitness in the majority of high quality studies, and that PA brought about significant beneficial changes in fat percentage and waist circumference as well as reducing risk of cardiovascular disease in obese adolescents. To supplement, a prospective longitudinal study showed that moderate-to-vigorous-levels of PA were negatively associated with fat mass for children aged 12 years two years later, with around $10 \%$ lower levels of fat mass [23].

Obesity is also negatively associated with the level of MC and performance of FMS [21] [24] [25] [26] [27]. Based on a recent systematic review including both cross-sectional and longitudinal studies, Liang, et al. [21] emphasized that the level of MC in the performance of object control skills, locomotion skills, and other motor abilities (e.g., balance) had strong negative associations with obesity in children and adolescents (aged 518 ). To explore the association between MC and BMI, Lopes and colleagues conducted two large scale cross-sectional studies analysing over 7000 children aged 6 11 [26] and 6 - 14 [27]. Children with better MC had significantly lower levels of BMI regardless of sex [26] [27]. Similarly, two longitudinal studies by D'Hondt and colleagues [24] [25] demonstrated that the significant reciprocal relationship between MC 
and BMI for children aged 6 - 10 [25] and 7 - 13 [24] continued at two years follow-up, and obese and overweight children had larger MC deficit than normal weight children across their developmental timeline [25]. Considered together, these studies provided evidence to suggest that $\mathrm{MC}$ does not necessarily develop or improve unless there is specific targeted exposure or intervention, and the accumulation of body mass over time in childhood and adolescence constrain further MC development and further engrain the vicious cycle.

However, PA is positively associated with MC and FMS levels. Two systematic reviews [19] [20] have identified that higher PA participation was associated with higher FMS competency in children aged 3 - 18. Similarly, a recent large scale cross-sectional study of around 7000 children aged 7 - 14 [28] demonstrated that low PA levels were strongly correlated with poor performance of FMS. Further, in a longitudinal study, Lopes, et al. [22] found that children at the highest tertiles of MC maintained their PA levels over a three-year period, while those at both middle and lower MC tertiles decreased PA over the same period. These findings provide evidence to suggest that MC development influences PA participation.

To summarize, and as shown in, there is coherent and clear evidence that obesity is negatively associated with PA, MC and level of performance of FMS. A low PA level is also related to inferior MC when performing FMS, contributing to the vicious cycle of increasing obesity. Therefore, developing good MC in various FMS in childhood is very important to protect against being caught in the vicious cycle and to minimise exacerbation of vicious cycle effects.

\subsection{How Can the Vicious Cycle Be Broken?}

In view of the evidence [16]-[28] that many overweight and obese children and adolescents are caught in a vicious cycle of obesity characterised by, and driven by, low levels of movement competence and participation in PA, it is necessary to look closely at how the cycle can be broken. Increasing and engaging in PA is an obvious means of reducing obesity by increasing energy expenditure [13] [29] [36], and is supported by the negative association between obesity and PA identified in the literature [16] [17] [18] [23]. However, a recent meta-analysis showed that the effectiveness of interventions designed to increase overall daily PA level (measured objectively instead of recall) for children (age $\leq 16$ ) was small and the interventions had little effect on BMI or reduction of body fat [14]. Further, Skelton and Beech [37] reported in a recent review that the attrition rate of childhood weight management programmes can be up to $73 \%$. More importantly, PA and FMS interventions to date have been unable to reach and sustain the moderate to vigorous PA required to reduce obesity or overweight [14] [38].

Therefore, an alternate strategy is to enhance both FMS proficiency and PA sustainability [38], to determine the effective characteristics of interventions [34] and to promote regular PA of obese individuals [25]. Given that $\mathrm{MC}$ has a critical position in the vicious cycle, training $\mathrm{MC}$ must be prominent in the strategy to promote PA and maintain a healthy energy balance [27]. To optimise the effectiveness of MC training, 
careful consideration must be accorded to the characteristics of MC programs and the pedagogical approach to ensure that "psycho-social conditions" are favourable and conducive to their long term success [39].

\section{Characteristics of an MC Training Program}

\subsection{Tailored Content According to MC Needs of Children}

To determine individual or group needs and shape program content, the initial task prior to any training or intervention should be to assess the level, degree and range of present MC capabilities. Program inclusion and grouping based on MC assessments could help reduce the emphasis on current weight status, and similarly assist peer group interaction and social-cohesion and participation, as individuals will be at similar developmental stages.

Current MC assessments are typically achieved through validated field assessments (e.g. Körperkoordinationstestfür [25] [40] or FMS assessment checklists [41]). However, the testing criteria are non-specific and results provide little information to assessors regarding the MC deficit to enable design of constructive interventions. We suggest using an evidence-based checklist which take objective and readily observed MC characteristics [42] into account that are known to be related to performance outcomes (e.g. speed, accuracy). Although based on scientific analysis, the list must be "practitioner friendly" with characteristics of appropriate movement patterns being observable and readily identifiable. Also teachers can be guided by general principles based on biomechanics analyses [43] [44] [45], developmental sequences [33] and qualitative movement analyses [46] to maximise individual performance in specific activities. For example, if speed is the goal when projecting objects, such as in throwing, kicking, or striking skills, the teacher would encourage the gradual increase in the "degrees of freedom" [31] utilised, range of motion, and sequencing of body segment motions [47]. Typical developmental patterns reflect that process [33]. For example, a novice throwing a ball is likely to start the throwing action with the body square to the intended direction of throw and would use the upper limbs as a single lever in a "push-like" action entirely in front of the body [48]. The movements of the limbs would tend to be simultaneous rather than sequenced. With practice, the joints would be "freed" and move through a larger range of linear and angular motion commencing with a step, trunk rotation counter to the eventual rotation, and a long backward reach. The movement then progresses in a "whip-like" proximal to distal sequence with rapid rotation of the lower and upper trunk, rotation of the upper arm about the shoulder, extension of the elbow and pronation and flexion of the wrist. It is a relatively simple task for a teacher or coach to identify the stage of learning in terms of the degrees of freedom used, the range of motion, and the sequencing. Then, training practices can be selected to continue the development of the skill.

Accuracy is often another goal of the movement and has implications for the movement pattern adopted. Staying with throwing as an example, the movement may be adapted to ensure accuracy by having a linear path of the hand in the approach to re- 
lease. The need for accuracy acts as a constraint that influences the movement pattern [49]. This is manifest in a baseball pitch in which the hand is moved in a vertical rather than horizontal plane.

Skilled performance requiring both speed and accuracy integrated with good sequencing and timing, for example, a golf swing or a tennis serve, would reflect both influences. Due to the accuracy constraint, use of a large number of joint degrees of freedom and large ranges of joint motions might only occur at the very high levels of performance. That is, only the highly skilled golf players can hit both long and straight.

The implications for teaching are that teachers need to create activities based on MC principles that develop appropriate movement patterns in a gradual fashion, recognising that increasing the use of the joint degrees of freedom, increasing ranges of joint motion, and developing good sequencing cannot be attained spontaneously. A graded process tailored to the individual's current ability and stage of learning is required.

\subsection{Pedagogical Approach Using Psycho-Social Climate Support}

As reported in a number of systematic reviews, school-based training is a good starting point for intervening as there is evidence that positive effects are associated with both PA [38] [50] and FMS interventions [38] [51] in this setting. However, many studies did not provide information relating to the rationale and desired characteristics of the pedagogical approach on which the intervention was based [51].

Based on a review, Teixeira, et al. [39] highlighted that psycho-social climates promoting high autonomous activation, self-efficacy and self-regulation skills were the best predictors for long-term ( $\geq 1$ year) PA behaviour adoption in obese adults. Similarly, Lubans, et al. [52] highlighted how varying psychological perspectives can inform the creation of a supportive psycho-social climate. These include self-determination [53] [54] [55], achievement goal theory [56] [57] [58]; behaviour change models and principles drawn from positive and youth psychology [59] [60]. Due to their relevancy, self-determination and achievement goal perspectives are now considered.

The self-determination perspective predicts that adherence can be facilitated by social processes which ensure that individual psychological needs (i.e. competency, autonomy and relatedness) are met. To develop competency, MC training needs to be characterized by a combination of self-assessment and supportive personalised feedback to help gauge progress (i.e., people need to feel and see that they are learning and developing). For autonomy, it is recommended that training offers opportunities for self-exploration and problem-solving in discovering different movement possibilities and ways of moving. Self-choice and volition in MC training, where possible, can also assist autonomy. For relatedness, a shared exploration and problem-solving experience with others should feature, alongside encouraging and caring instructors. A shared social and emotional experience in and around training will help. Together, these characteristics of the program are predicted to heighten perceptions of connection, relatedness, and inclusion, but will need to be frequent, repeated, and positively reinforced. Accordingly, the outcome over time is self-motivated (intrinsic) behaviour, where 
self-volition, initiative, enjoyment and satisfaction are outcomes, and which subsequently motivate onward adherence.

The achievement goal perspective assumes individuals need to develop competence via personal mastery or social recognition. And to promote task interest, cognitive engagement, effort and persistence, learning, and better emotional outcomes, this perspective recommends the creation of a "task based climate" [58]. Compared to a "performance (ego-based) social recognition climate", task climates focus on personal skill mastery within and across an intentionally diverse range of training activities introduced with task novelty and variety. Here, learners are jointly responsible for their learning experiences, and are directly involved in the training and learning in regards to themselves and others. Personal effort, strategy, trial and error testing, peer-led training, shared investigation and discovery, and high social interaction are encouraged and emphasized in this climate. Individuals monitor their own progress (self-regulate) using their own effort, strategy and progress as referent criteria. In task based climates, social judgement, labelling, and competency fixation are avoided. Social comparison, external reward (e.g., by an observer/instructor) and the idea of not being able to change or develop, i.e., a fixed mind set [61], is absent from this climate. Therefore, the main aim of MC training in a task-based psycho-social climate is to generate perceptions of personal skill betterment, fulfilment, and satisfaction from improved mastery or competence, along with improved future expectations (i.e., autonomy and efficacy).

Psycho-social climates could be assessed and evaluated using validated instruments to help optimise MC training delivery by maximising participation and adherence. For instance, in the initial and short-term phases of training, emotional and social experiences, such as fun and enjoyment, sense of inclusion, and belonging, may be important as they support and encourage participation. Tracking perceived efficacy [39] and competency development, objectively and subjectively [62], as well as personal satisfaction [62] [63] across the short and longer-term would seem valuable, as these have been identified as possible key influences to adherence. The ultimate goal is to enable eventual mainstream peer group activities and sports activities with improving MC.

\section{Implications}

Physical education programmes or exercise prescription for children with and without obesity should consider the specific MC and FMS development needs of individuals. The pedagogical approach should emphasise a task-based psycho-social climate. This helps to increase PA adherence and enables enjoyable participation in peer group games and sports. The training sessions should focus on MC of the fundamental movements with psycho-social climate support to maximize the outcome.

Further research can evaluate the effectiveness of this pedagogical approach for achieving improvement in motor skills, PA adherence and psychometric effects. The motor skills assessment should be both process and product orientated to provide an overall picture of the movement and skills performances. Although schools are the ideal settings for this approach, it can also be applied to rehabilitation programmes for obese 
or overweight children in clinical or community settings.

\section{Conclusion}

Implementing MC and FMS training could be a useful strategy to break the vicious cycle of obesity and enhance long-term PA adherence amongst overweight and obese children. MC training should be tailored to meet the MC needs of individuals based on objective assessment of their FMS abilities. The program should be delivered in a non-competitive task climate emphasising self-efficacy, self-regulation and enjoyment of participation in PA.

\section{Acknowledgements}

The authors would like to thank Ms. Y. Tam, Academic Liaison Librarian from the Health Sciences Library of the University of Sydney, for her invaluable assistance with the literature searches.

\section{Funding Source}

No funding source exist. Mr. Fu holds an International Postgraduate Research Scholarship and a Postgraduate Awards from the Australian Government for his Ph.D. candidature.

\section{References}

[1] World Health Organization (2015) Overweight and Obesity. http://www.who.int/mediacentre/factsheets/fs311/en/\#

[2] Ng, M., Fleming, T., Robinson, M., Thomson, B., Graetz, N., Margono, C., et al. (2014) Global, Regional, and National Prevalence of Overweight and Obesity in Children and Adults during 1980-2013: A Systematic Analysis for the Global Burden of Disease Study 2013. The Lancet, 384, 766-781. http://dx.doi.org/10.1016/S0140-6736(14)60460-8

[3] Kelly, T., Yang, W., Chen, C.S., Reynolds, K. and He, J. (2008) Global Burden of Obesity in 2005 and Projections to 2030. International Journal of Obesity, 32, 1431-1437. http://dx.doi.org/10.1038/ijo.2008.102

[4] Dee, A., Kearns, K., O'Neill, C., Sharp, L., Staines, A., O’Dwyer, V., et al. (2014) The Direct and Indirect Costs of Both Overweight and Obesity: A Systematic Review. BMC Research Notes, 7, 242-242. http://dx.doi.org/10.1186/1756-0500-7-242

[5] Withrow, D. and Alter, D.A. (2011) The Economic Burden of Obesity Worldwide: A Systematic Review of the Direct Costs of Obesity. Obesity Reviews, 12, 131-141. http://dx.doi.org/10.1111/j.1467-789X.2009.00712.x

[6] Herman, K.M., Craig, C.L., Gauvin, L. and Katzmarzyk, P.T. (2009) Tracking of Obesity and Physical Activity from Childhood to Adulthood: The Physical Activity Longitudinal Study. International Journal of Pediatric Obesity, 4, 281-288. http://dx.doi.org/10.3109/17477160802596171

[7] Suchindran, C., North, K.E., Popkin, B.M. and Gordon-Larsen, P. (2010) Association of Adolescent Obesity with Risk of Severe Obesity in Adulthood. JAMA, 304, 2042-2047.

[8] Reilly, J.J. and Kelly, J. (2011) Long-Term Impact of Overweight and Obesity in Childhood and Adolescence on Morbidity and Premature Mortality in Adulthood: Systematic Review. 
International journal of obesity, 35, 891-898. http://dx.doi.org/10.1038/ijo.2010.222

[9] Park, M., Falconer, C., Viner, R. and Kinra, S. (2012) The Impact of Childhood Obesity on Morbidity and Mortality in Adulthood: A Systematic Review. Obesity Reviews, 13, 985 1000. http://dx.doi.org/10.1111/j.1467-789X.2012.01015.x

[10] Sanders, R.H., Han, A., Baker, J.S. and Cobley, S. (2015) Childhood Obesity and Its Physical and Psychological Co-Morbidities: A Systematic Review of Australian Children and Adolescents. European Journal of Pediatrics, 174, 715-746. http://dx.doi.org/10.1007/s00431-015-2551-3

[11] Forhan, M. and Gill, S.V. (2013) Obesity, Functional Mobility and Quality of Life. Best Practice \& Research: Clinical Endocrinology \& Metabolism, 27, 129-137. http://dx.doi.org/10.1016/j.beem.2013.01.003

[12] Wang, L.Y., Denniston, M., Lee, S., Galuska, D. and Lowry, R. (2010) Long-Term Health and Economic Impact of Preventing and Reducing Overweight and Obesity in Adolescence. Journal of Adolescent Health, 46, 467-473. http://dx.doi.org/10.1016/j.jadohealth.2009.11.204

[13] World Health Organization (2009) Who Guidelines Approved by the Guidelines Review Committee. Interventions on Diet and Physical Activity: What Works: Summary Report, World Health Organization, Geneva.

[14] Metcalf, B., Henley, W. and Wilkin, T. (2012) Effectiveness of Intervention on Physical Activity of Children: Systematic Review and Meta-Analysis of Controlled Trials with Objectively Measured Outcomes (Earlybird 54). BMJ, 345.

[15] Salmon, J., Booth, M.L., Phongsavan, P., Murphy, N. and Timperio, A. (2007) Promoting Physical Activity Participation among Children and Adolescents. Epidemiologic Reviews, 29, 144-159. http://dx.doi.org/10.1093/epirev/mxm010

[16] Jiménez-Pavón, D., Kelly, J. and Reilly, J.J. (2010) Associations between Objectively Measured Habitual Physical Activity and Adiposity in Children and Adolescents: Systematic Review. International Journal of Pediatric Obesity, 5, 3-18. http://dx.doi.org/10.3109/17477160903067601

[17] Prentice-Dunn, H. and Prentice-Dunn, S. (2011) Physical Activity, Sedentary Behavior, and Childhood Obesity: A Review of Cross-Sectional Studies. Psychology, Health \& Medicine, 17, 255-273. http://dx.doi.org/10.1080/13548506.2011.608806

[18] Vasconcellos, F., Seabra, A., Katzmarzyk, P., Kraemer-Aguiar, L., Bouskela, E. and Farinatti, P. (2014) Physical Activity in Overweight and Obese Adolescents: Systematic Review of the Effects on Physical Fitness Components and Cardiovascular Risk Factors. Sports Medicine, 44, 1139-1152. http://dx.doi.org/10.1007/s40279-014-0193-7

[19] Lubans, D.R., Morgan, P.J., Cliff, D.P., Barnett, L.M. and Okely, A.D. (2010) Fundamental Movement Skills in Children and Adolescents. Sports Medicine, 40, 1019-1035. http://dx.doi.org/10.2165/11536850-000000000-00000

[20] Holfelder, B. and Schott, N. (2014) Relationship of Fundamental Movement Skills and Physical Activity in Children and Adolescents: A Systematic Review. Psychology of Sport and Exercise, 15, 382-391. http://dx.doi.org/10.1016/j.psychsport.2014.03.005

[21] Liang, J., Matheson, B.E., Kaye, W.H. and Boutelle, K.N. (2014) Neurocognitive Correlates of Obesity and Obesity-Related Behaviors in Children and Adolescents. International Journal of Obesity, 38, 494-506. http://dx.doi.org/10.1038/ijo.2013.142

[22] Lopes, V.P., Rodrigues, L.P., Maia, J.A. and Malina, R.M. (2011) Motor Coordination as Predictor of Physical Activity in Childhood. Scandinavian Journal of Medicine and Science in Sports, 21, 663-669. http://dx.doi.org/10.1111/j.1600-0838.2009.01027.x 
[23] Riddoch, C.J., Leary, S.D., Ness, A.R., Blair, S.N., Deere, K., Mattocks, C., et al. (2009) Prospective Associations between Objective Measures of Physical Activity and Fat Mass in 12 14 Year Old Children: The Avon Longitudinal Study of Parents and Children (ALSPAC). BMJ, 339, b4544. http://dx.doi.org/10.1136/bmj.b4544

[24] D’Hondt, E., Deforche, B., Gentier, I., Verstuyf, J., Vaeyens, R., De Bourdeaudhuij, I., et al. (2014) A Longitudinal Study of Gross Motor Coordination and Weight Status in Children. Obesity, 22, 1505-1511. http://dx.doi.org/10.1002/oby.20723

[25] D’Hondt, E., Deforche, B., Gentier, I., De Bourdeaudhuij, I., Vaeyens, R., Philippaerts, R. and Lenoir, M. (2013) A Longitudinal Analysis of Gross Motor Coordination in Overweight and Obese Children versus Normal-Weight Peers. International Journal of Obesity, 37, 61-67. http://dx.doi.org/10.1038/ijo.2012.55

[26] Lopes, V.P., Stodden, D.F. and Rodrigues, L.P. (2014) Weight Status Is Associated with Cross-Sectional Trajectories of Motor Co-Ordination across Childhood. Child: Care, Health and Development, 40, 891-899. http://dx.doi.org/10.1111/cch.12127

[27] Lopes, V.P., Stodden, D.F., Bianchi, M.M., Maia, J.A. and Rodrigues, L.P. (2012) Correlation between BMI and Motor Coordination in Children. Journal of Science and Medicine in Sport, 15, 38-43. http://dx.doi.org/10.1016/j.jsams.2011.07.005

[28] Hardy, L.L., Reinten-Reynolds, T., Espinel, P., Zask, A. and Okely, A.D. (2012) Prevalence and Correlates of Low Fundamental Movement Skill Competency in Children. Pediatrics, 130, e390-e398. http://dx.doi.org/10.1542/peds.2012-0345

[29] Longmuir, P.E., Colley, R.C., Wherley, V.A. and Tremblay, M.S. (2014) Canadian Society for Exercise Physiology Position Stand: Benefit and Risk for Promoting Childhood Physical Activity. Applied Physiology, Nutrition, and Metabolism, 39, 1271-1279. http://dx.doi.org/10.1139/apnm-2014-0074

[30] Okely, A.D., Salmon, J., Vella, S.A., Cliff, D., Timperio, A., Tremblay, M., et al. (2012) A Systematic Review to Update the Australian Physical Activity Guidelines for Children and Young People. The Department of Health, Canberra, Australia.

[31] Bernstein, N. (1967) The Co-Ordination and Regulation of Movement. Pergamon Press, Oxford.

[32] Turvey, M.T. (1990) Coordination. American Psychologist, 45, 938-953. http://dx.doi.org/10.1037/0003-066X.45.8.938

[33] Gallahue, D.L., Ozmun, J.C. and Goodway, J. (2012) Understanding Motor Development: Infants, Children, Adolescents, Adults. McGraw-Hill, New York.

[34] Logan, S.W., Robinson, L.E., Wilson, A.E. and Lucas, W.A. (2012) Getting the Fundamentals of Movement: A Meta-Analysis of the Effectiveness of Motor Skill Interventions in Children. Child: Care, Health and Development, 38, 305-315. http://dx.doi.org/10.1111/j.1365-2214.2011.01307.x

[35] O’Keeffe, S.L., Harrison, A.J. and Smyth, P.J. (2007) Transfer or Specificity? An Applied Investigation into the Relationship between Fundamental Overarm Throwing and Related Sport Skills. Physical Education and Sport Pedagogy, 12, 89-102. http://dx.doi.org/10.1080/17408980701281995

[36] American College of Sports Medicine (2013) ACSM's Guidelines for Exercise Testing and Prescription. Lippincott Williams \& Wilkins, Philadelphia, USA.

[37] Skelton, J. and Beech, B. (2011) Attrition in Paediatric Weight Management: A Review of the Literature and New Directions. Obesity Reviews, 12, e273-e281.

http://dx.doi.org/10.1111/j.1467-789x.2010.00803.x

[38] Lai, S., Costigan, S., Morgan, P., Lubans, D., Stodden, D., Salmon, J., et al. (2014) Do 
School-Based Interventions Focusing on Physical Activity, Fitness, or Fundamental Movement Skill Competency Produce a Sustained Impact in These Outcomes in Children and Adolescents? A Systematic Review of Follow-Up Studies. Sports Medicine, 44, 67-79. http://dx.doi.org/10.1007/s40279-013-0099-9

[39] Teixeira, P.J., Carraça, E.V., Marques, M.M., Rutter, H., Oppert, J.-M., De Bourdeaudhuij, I., et al. (2015) Successful Behavior Change in Obesity Interventions in Adults: A Systematic Review of Self-Regulation Mediators. BMC Medicine, 13, 84. http://dx.doi.org/10.1186/s12916-015-0323-6

[40] D'Hondt, E., Gentier, I., Deforche, B., Tanghe, A., Bourdeaudhuij, I.D. and Lenoir, M. (2011) Weight Loss and Improved Gross Motor Coordination in Children as a Result of Multidisciplinary Residential Obesity Treatment. Obesity, 19, 1999-2005. http://dx.doi.org/10.1038/oby.2011.150

[41] Department of Education Western Australia (2013) Fundamental Movement Skills: Book 2 - The Tools for Learning, Teaching and Assessment. Department of Education.

[42] Robertson, D.G.E. (2014) Research Methods in Biomechanics. Human Kinetics, Champaign, IL.

[43] Sanders, R.H. (2004) Biomechanical Analyses in Physical Education. In: Wirght, J., MacDonald, D. and Burrows, L., Eds., Critical Inquiry and Problem Solving in Physical Education: Working with Students in Schools, Routledge, New York, 159-170.

[44] Knudson, D.V. (2007) Qualitative Biomechanical Principles for Application in Coaching. Sports Biomechanics, 6, 109-118. http://dx.doi.org/10.1080/14763140601062567

[45] Hudson, J.L. (1995) Core Concepts of Kinesiology. Journal of Physical Education, Recreation and Dance, 66, 54-60. http://dx.doi.org/10.1080/07303084.1995.10607081

[46] Knudson, D.V. (2013) Qualitative Analysis of Human Movement: Diagnosing Performance in Sport and Exercise. Human Kinetics, Champaign, IL.

[47] Putnam, C.A. (1993) Sequential Motions of Body Segments in Striking and Throwing Skills: Descriptions and Explanations. Journal of Biomechanics, 26, 125-135.

http://dx.doi.org/10.1016/0021-9290(93)90084-R

[48] Krieghbaum, E. and Barthels, K.M. (1981) Biomechanics a Qualitative Approach for Studying Human Movement. Burgess Publishing Company, USA.

[49] Heitz, R.P. (2014) The Speed-Accuracy Tradeoff: History, Physiology, Methodology, and Behavior. Frontiers in Neuroscience, 8, 150. http://dx.doi.org/10.3389/fnins.2014.00150

[50] Dobbins, M., Husson, H., DeCorby, K. and LaRocca, R.L. (2013) School-Based Physical Activity Programs for Promoting Physical Activity and Fitness in Children and Adolescents Aged 6 to 18. Cochrane Database of Systematic Reviews, 2, CD007651.

[51] Morgan, P.J., Barnett, L.M., Cliff, D.P., Okely, A.D., Scott, H.A., Cohen, K.E., et al. (2013) Fundamental Movement Skill Interventions in Youth: A Systematic Review and MetaAnalysis. Pediatrics, 132, e1361-e1383. http://dx.doi.org/10.1542/peds.2013-1167

[52] Lubans, D.R., Foster, C. and Biddle, S.J. (2008) A Review of Mediators of Behavior in Interventions to Promote Physical Activity among Children and Adolescents. Preventive Medicine, 47, 463-470. http://dx.doi.org/10.1016/j.ypmed.2008.07.011

[53] Deci, E.L. and Ryan, R.M. (1985) Intrinsic Motivation and Self-Determination in Human Behavior. Springer Science \& Business Media, USA. http://dx.doi.org/10.1007/978-1-4899-2271-7

[54] Ryan, R.M. and Deci, E.L. (2000) Self-Determination Theory and the Facilitation of Intrinsic Motivation, Social Development, and Well-Being. American Psychologist, 55, 68-78. http://dx.doi.org/10.1037/0003-066X.55.1.68 
[55] Vallerand, R.J. (1997) Toward a Hierarchical Model of Intrinsic and Extrinsic Motivation. Advances in Experimental Social Psychology, 29, 271-360. http://dx.doi.org/10.1016/S0065-2601(08)60019-2

[56] Ames, C. (1992) Classrooms: Goals, Structures, and Student Motivation. Journal of Educational Psychology, 84, 261-271. http://dx.doi.org/10.1037/0022-0663.84.3.261

[57] Dweck, C.S. and Leggett, E.L. (1988) A Social-Cognitive Approach to Motivation and Personality. Psychological Review, 95, 256-273. http://dx.doi.org/10.1037/0033-295X.95.2.256

[58] Nicholls, J.G. (1984) Achievement Motivation: Conceptions of Ability, Subjective Experience, Task Choice, and Performance. Psychological Review, 91, 328-346. http://dx.doi.org/10.1037/0033-295X.91.3.328

[59] Linley, P.A. and Joseph, S. (2004) Positive Change Following Trauma and Adversity: A Review. Journal of Traumatic Stress, 17, 11-21. http://dx.doi.org/10.1023/B:JOTS.0000014671.27856.7e

[60] Holt, N.L. (2016) Positive Youth Development through Sport. Routledge, New York, London.

[61] Dweck, C.S. (2012) Mindset: How You Can Fulfil Your Potential. Constable \& Robinson, London.

[62] Toftegaard-Stoeckel, J., Groenfeldt, V. and Andersen, L.B. (2010) Children's Self-Perceived Bodily Competencies and Associations with Motor Skills, Body Mass Index, Teachers' Evaluations, and Parents' Concerns. Journal of Sports Sciences, 28, 1369-1375. http://dx.doi.org/10.1080/02640414.2010.510845

[63] Morano, M., Colella, D. and Capranica, L. (2011) Body Image, Perceived and Actual Physical Abilities in Normal-Weight and Overweight Boys Involved in Individual and Team Sports. Journal of Sports Sciences, 29, 355-362. http://dx.doi.org/10.1080/02640414.2010.530678

Submit or recommend next manuscript to SCIRP and we will provide best service for you:

Accepting pre-submission inquiries through Email, Facebook, LinkedIn, Twitter, etc.

A wide selection of journals (inclusive of 9 subjects, more than 200 journals)

Providing 24-hour high-quality service

User-friendly online submission system

Fair and swift peer-review system

Efficient typesetting and proofreading procedure

Display of the result of downloads and visits, as well as the number of cited articles

Maximum dissemination of your research work

Submit your manuscript at: http://papersubmission.scirp.org/

Or contact jss@scirp.org 